acetate, with subsequent contamination of the product by acetate ion, and it was advisable to remove ethyl acetate from the aqueous layer by one final extraction with ether $(200 \mathrm{ml}$.).

The aqueous solution was then neutralized with sodium hydroxide and evaporated to give a colourless glass, which crystallized from 88 per cent alcohol $(160 \mathrm{ml}$.) and ether $(90 \mathrm{ml}$.$) on chilling overnight, in$ rosettes of needles (16 gm.). Paper chromatography ${ }^{2}$ of this purified material revealed about 1 per cent taurodeoxycholate, but no detectable (that is $<0.5$ per cent) unconjugated acids.

\section{G. ANDERson}

Guy's Hospital Medical School, London, S.E.1.

${ }^{1}$ Norman, A., Arkiv för Kemi, 8, 331 (1955).

${ }^{2}$ Haslewood, G. A. D., and Sjovvall, J., Biochem. J., 57, 126 (1954).

\section{Successive Stages of a Graphite-Potassium Compound and its Thermal Expansion}

Graphite and potassium amalgamate easily, resulting in golden crystals, and the colour changes to brown, then to dark blue as the potassium is driven off by heating. Schleede and Wellmann ${ }^{1}$ analysed two stable forms of the lamellar compounds with intercalated potassium atoms in one and two graphite layers respectively. Later, higher stages up to five were analysed ${ }^{2}$ with the less controllable compounds of graphite-sulphuric acid. Quite recently, Hooley ${ }^{3}$ proposed a sealed-edge theory to account for the stepwise formation of the compounds concerned. I have also been interested in this point and have performed some experiments which will be described here.

Graphite powder with excess potassium was sealed in one end of a thin glass tube having an outside diameter of $1.2 \mathrm{~mm}$. and then the potassium was slowly driven off or absorbed again by local heating. A high-temperature powder-camera of $24 \mathrm{~cm}$. diameter and filtered molybdenum radiation were used.

Observed diffraction lines having indices $(00 l)$ are shown in Fig. 1, where the orders are indicated on the left side of respective stages. The order of a stage is equal to the number of graphite layers between nearest potassium layers. Stage 1 was obtained after heating for $12 \mathrm{hr}$. at $200^{\circ}$ or at $300^{\circ} \mathrm{C}$. The heating was continued and stages 2 and 3 appeared during $24 \mathrm{hr}$. at $365^{\circ} \mathrm{C}$. Stages 4 and 5 appeared successively during the next $49 \mathrm{hr}$. at $400^{\circ} \mathrm{C}$. Stage 6 appeared after $24 \mathrm{hr}$. at $420^{\circ} \mathrm{C}$. Stages 7, 8, 9 and 10 appeared successively during prolonged heating at $440^{\circ} \mathrm{C}$. for $76 \mathrm{hr}$. In this series of steps overlapping patterns were observed only between stages 1 and 2 . The time of heating to get a certain stage is subject to many factors and differed for different series of experiments.

The spacings of the doublet lines appearing on the left side of each stage agree with the values calculated by the following formulæ within the errors of experiment:

$$
\frac{5 \cdot 32+3 \cdot 37(n-1)}{n}, \frac{5 \cdot 32+3 \cdot 37(n-1)}{n+1}
$$

where $n$ is the order of the stage. As shown in Fig. 1 stepping up of the stage is suddenly broken at stage 11 by the appearance of the stronger 002 line of graphite, while the higher order line of the doublet still remains in this transient state, and it disappeared completely

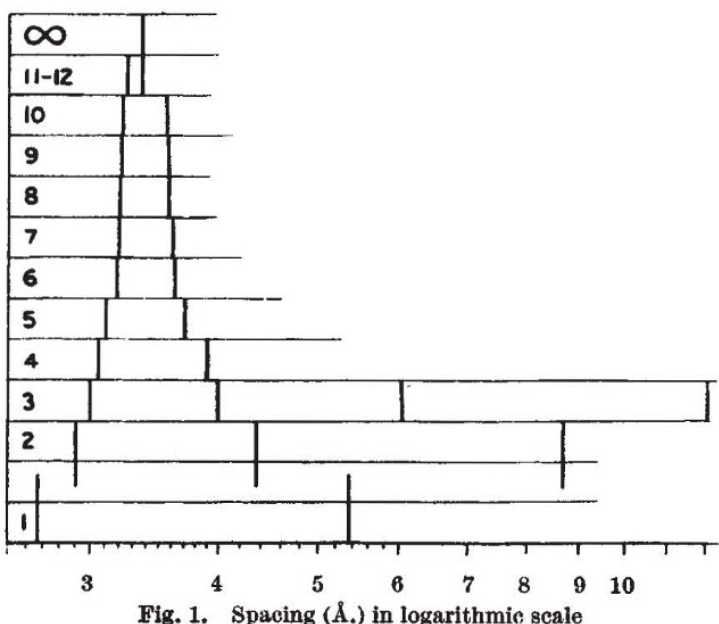

after further heating for $24 \mathrm{hr}$. at $440^{\circ} \mathrm{C}$. This point was confirmed by repeated experiments and it has been concluded that in the range beyond stage 10 the forces to hold potassium atoms periodically between graphite layers are overcome by the thermal motion.

The temperature shifts of the pairs of lines were observed using a short specimen tube containing sufficient amount of potassium for stage 1 and heating uniformly in an aluminium furnace at temperatures ranging from $15^{\circ}$ to $340^{\circ} \mathrm{C}$. Since the shifts occurred reversibly it was considered to be due to the true thermal expansion in the $c$-direction, and the coeffi. cient has been estimated to be $47 \times 10^{-6} \pm 7 \times 10^{-6}$, the value being fairly large when compared with $27 \times 10^{-6}$ for graphite ${ }^{4}$. As would be expected smaller shifts were observed also in stage 2; however, the coefficient had not been determined because of the experimental difficulties encountered.

Faculty of Engineering,

Yamaguchi University, Ube, Japan.

${ }^{1}$ Schleede, A., and Wellmann, M., Z. phys. Chem.. B, 18, 1 (1932). ${ }^{2}$ Rüdorff, W., and Hofmann, U., $Z$. anorg. allg. Chem., 238, 1 (1938). ${ }^{3}$ Hooley, J. G., Nature, 190, 529 (1961).

4 Steward, E. G., Nature, 185, 78 (1960).

\section{Dependence on Temperature of Hyperfine} Couplings in the Free Radical $\mathrm{SO}_{3}{ }^{-}-\mathbf{N}_{2}{ }^{+}$

IN connexion with a study of the electron spin resonance spectrum of the free radical $\mathrm{SO}_{3}^{-}$, the spectrum of a single crystal of sulphamic acid $\mathrm{SO}_{3}-\mathrm{NH}_{3}{ }^{+}$irradiated with 1-MeV. $\gamma$-rays was examined in an $X$ band spectrometer. In addition to the line $g=2 \cdot 004$, attributed to $\mathrm{SO}_{3}{ }^{-}$, a wide hyperfine pattern was observed. Observations at $300^{\circ} \mathrm{K}$. were consistent with the presence of the radical $\mathrm{SO}_{3}--\mathrm{NH}_{2}{ }^{+}$, in four magnetically inequivalent sites in accordance with the orthorhombic unit cell ${ }^{1}$. The hydrogens were wholly equivalent at all orientations, indicating ${ }^{2}$ 'rotation' about the $\mathrm{S}-\mathrm{N}$ bond. The principal directions of the nitrogen and hydrogen coupling tensors were parallel within the experimental error. The largest nitrogen coupling is expected to be perpendicular to the plane of the $-\mathrm{NH}_{2}^{+}$group, and the largest hydrogen coupling along the $\mathrm{S}-\mathrm{N}$ bond direction. The details are given in Table 1 , and the direction 